\title{
Licensing Telemedicine: The Need for a National System
}

\author{
PETER D. JACOBSON, J.D., M.P.H., and ELIZABETH SELVIN
}

\begin{abstract}
The expansion of information technology has shattered geographic boundaries, allowing for extraordinarily increased access to health information and expanded opportunities for telemedicine practice across state boundaries. But despite its recent growth, telemedicine technology remains embedded in a state-based licensure system that places severe limits on its expansion. The current system of medical licensure is based primarily on statutes written at the turn of the $20^{\text {th }}$ century. This system is inadequate to address the emerging medical practices and future uses of medical technology in the telecommunications age. To respond to the changes offered by the telecommunications revolution, we need to design a new regulatory structure for the $21^{\text {st }}$ century. The purpose of this article is to propose a policy of national telemedicine licensure. The primary goal here is not to simply develop a policy proposal, but to discuss the rationale for national licensure and place it on the policy agenda. A national licensure system will expand the market for telemedicine, promote both the use and development of new technologies, and simultaneously eliminate many of the legal and regulatory ambiguities that plague and constrain the present system.
\end{abstract}

\section{INTRODUCTION}

$\mathbf{T}$ HE EXPANSION OF INFORMATION TECHNOLOGY has shattered geographic boundaries, allowing for extraordinarily increased access to health information and expanded opportunities for medical practice across state boundaries. As one manifestation of this trend, the growth and popularity of the Internet has spurred travel of vast amounts of health and health-related information across the nation and throughout the world, including on-line medical dictionaries, health-related "chat" groups and Web sites, medical consultation and on-line pharmacies. These developments represent a dramatic departure from the traditional model of how medicine is practiced, raising difficult and contentious issues over liabil- ity, licensure, and cross-state medical practice. The relatively new and rapidly evolving field of telemedicine is an important, but also potentially controversial, microcosm of the application of information technology in health care.

Despite its recent growth, telemedicine remains ensnared in a state-based licensure system that places severe limits on its expansion. In this article, we argue that the state-based model is inadequate to address the emerging medical practices and future uses of medical technology in the information age. Because continued reliance on state-based licensure is detrimental to the development of telemedicine, we argue for an expanded national telemedicine licensure system to replace the current state-based model. 
The purpose of this article is to propose a policy of national telemedicine licensure. A new national model for licensing telemedicine is needed to facilitate the transforming possibilities of the telecommunications revolution, to expand opportunities for patients, and to allow the market to function most efficiently. Although we try to address many of the questions surrounding effective telemedicine licensure, ${ }^{1}$ our primary objectives are to articulate the rationale for national licensure and to place it on the national policy agenda.

\section{BACKGROUND}

\section{The promise of telemedicine}

Interest in telemedicine, defined more narrowly as medical diagnosis and treatment via information technology, has increased dramatically in the past decade. ${ }^{2}$ A quick search of Medline abstracts reveals that in 1990, only five articles mentioned "telemedicine," compared to 266 in 1998. The fields of radiology, cardiology, mental health, pathology, and dermatology have been particularly receptive to new telemedicine technologies. ${ }^{3}$

It is clear that telemedicine has tremendous potential. Kuszler, 4 for example, asserts that "telemedicine is poised to become an integral part of the health care industry." Already, telemedicine has allowed doctors to consult and diagnose patients across state lines via videoconferencing systems. It can reach isolated patients, such as prisoners or patients who are homebound or live in rural areas. Telemedicine has the capability to reduce geographic disparities in health services access by facilitating consultation and treatment with patients regardless of the location of the provider. Telemedicine has also been heralded as a way to enhance educational opportunities for medical professionals through "distance-learning" environments, connecting students in remote locations to demonstrations and instructional materials available at major academic health centers.

Several researchers have suggested that telemedicine technologies can reduce health care costs by allowing patients to be treated before a medical condition becomes severe, requiring expensive emergency treatment. ${ }^{2,5,6}$
Telemedicine allows for the rapid transfer of medical information, potentially saving time, speeding treatment, and reducing paperwork. ${ }^{7}$ Others, however, have questioned these costsavings claims. ${ }^{4,8}$ Weissert and Silberman ${ }^{8}$ note, for instance, that ". . . even if costs-percase are lowered, the tendency of new technologies to be applied to an ever-widening range of conditions means that overall use of services and costs will rise."

According to a special report by the Western Governor's Association, "telemedicine has been used effectively to improve public health in rural communities by providing timely information and training for rural county health departments." ${ }^{9}$ One proponent of telemedicine has suggested that "telemedicine just may be the panacea for the United States' health care ailments." 6 But regardless of whether telemedicine would be in a position to address all that ails the U.S. health care system, if barriers to expansion are removed this technology would provide immediate health care access to patients who may not otherwise receive appropriate care.

\section{General trends in the literature}

Telemedicine raises complex legal, social, and economic questions, most of which are currently being addressed in the professional literature. For example, analytic articles have been published on the legal and regulatory concerns $^{2,4}$ and research has begun to assess the cost-effectiveness, reliability, quality, and benefits of telemedicine technologies. ${ }^{10-14}$ At the same time, several publications have suggested that the lack of reimbursement and poor infrastructure planning and development have impeded the growth of telemedicine, ${ }^{5,15,16}$ as well as the state-based licensure system. Because the other legal issues surrounding telemedicine have been addressed at length elsewhere, we will present only a cursory view of the major legal issues here as background for the analysis of licensure issues.

\section{OVERVIEW OF THE LEGAL ISSUES}

This article implicitly assumes that policies facilitating telemedicine expansion will be ben- 
eficial to society. Yet, despite its promise and our expectations of its social value, the practice of telemedicine raises legitimate legal concerns that must be addressed. Indeed, Sanders and Bashshur $^{17}$ note that telemedicine is not constrained by technology per se but rather by the legal and social environment. In particular, the current legal and regulatory structures are not equipped to deal with the rapidly evolving information technology. And, because telemedicine is not constrained by geographic boundaries, it poses particular challenges. To provide a framework for the arguments made in this paper, we consider two of the most frequently discussed legal obstacles facing telemedicine.

\section{Medical malpractice liability}

As with most medical encounters, there is always the risk that negligent health care providers could harm patients during consultation, diagnosis, or treatment via telemedicine. When telemedicine crosses state borders, it poses troublesome jurisdictional questions. Which state law should apply? How can a practitioner from another state be sued where the patient resides? In addition, Kuszler ${ }^{4}$ points out that telemedicine consultations may involve more health providers than other medical situations, which "could potentially lead to confusion as to who is accountable for individual decisions and for the overall care of the patient."

Potential failures in technology, along with errors in entry or reading of data, suggest that telemedicine may also add another dimension to malpractice issues surrounding the use of medical technology. In particular, the wide variety of telemedicine technologies necessitates the need for a formal informed consent process that differs from the process currently applied to most individual medical procedures.

\section{Health information privacy}

The increasing number of stakeholders interested in having access to computerized data sources, including data transmitted across the Internet, means greater demand for access to information and greater opportunities for security breaches, either through hackers or through lax security procedures. State law cur- rently guards patient health information and medical data, but these laws vary widely across states. ${ }^{18}$ The necessary legal and regulatory structures are not in place to ensure data privacy and health information confidentiality, especially when medical information crosses state lines. ${ }^{19}$

\section{OVERVIEW OF LICENSING ISSUES}

The regulation of the practice of medicine has traditionally been a state responsibility. ${ }^{20}$ State medical boards, operating separately in each of the 50 states, license physicians and other health care professionals as a mechanism for ensuring the quality of medical practice. Medical boards establish entry requirements for the profession by granting permission to individuals who meet specified standards the legal right to practice medicine. On the basis of state-defined standards, medical boards regulate the scope of practice and quality of medical care, and enforce accountability of health care professionals. Those individuals who attempt to practice medicine without a license can be prosecuted for violating state law. Indeed, individuals who breach professional standards may be disciplined by state regulatory authorities.

The current state-based medical licensure system may constitute one of the most significant barriers to the wide dissemination of telemedicine. The state licensure system, which controls the right to practice medicine, is in direct conflict with telemedicine, which is inherently amenable to cross-state or national medical practice. Because each state may have different definitions for the "practice of medicine," physicians from one state may not be familiar with the regulations described by the medical practice act of another. These state licensure laws are fragmented and uncoordinated, hindering access to telemedicine services and discouraging further deployment of these systems. Consequently, the prevailing licensing system discourages physicians from practicing medicine across state lines. Absent some formal relationship with the patient's state, a physician who treats a patient across state borders would be considered practicing medicine without a license. A physician from 
one state who attempts to practice medicine in another may be at risk for violating state law when attending to patients in the distant state.

Additional restrictions may be imposed on physicians who attempt to consult in states where they are not licensed. For instance, when a physician licensed only in Michigan wants to consult on a case in Wisconsin, the latter may require the presence of a practitioner licensed in Wisconsin. Such restrictions have particular implications for telemedicine, potentially deterring physicians from engaging in telemedicine activities, and blocking patients in rural or other isolated situations from gaining access to needed health care services.

\section{LICENSURE MODELS}

Although numerous articles have described the purposes and history of medical professional licensure, ${ }^{20}$ few of them explicitly address the intersection of telemedicine and licensure. Those articles that do address problems associated with licensure for telemedicine are generally little more than commentaries supporting the status quo with a slate of general reasons for retaining the current state-based medical system. ${ }^{21-24}$

The telemedicine licensure models proposed in the literature do not fall into easily discernable categories. For instance, there is disagreement regarding the number and type of licensing models that can be applied to telemedicine activities. ${ }^{25,26}$ We have selected five models that seem to represent the range of possible approaches to telemedicine licensure: (1) full licensure; (2) endorsement, mutual recognition, and reciprocity agreements; (3) consultation exceptions; (4) special licensure; and (5) national licensure. Of these models, the first four are designed to retain the current state-based medical licensure system. The fifth represents a dramatic departure from current policy.

\section{Full licensure}

Full licensure requires health professionals practicing across state lines to obtain full and unrestricted licenses in all states in which they plan to consult, diagnose, and / or treat patients.
This model wholly retains the current statebased medical licensure system. In 1998, 15 states explicitly required full licensure for physicians practicing interstate telemedicine. ${ }^{27}$

\section{Consultation exceptions}

Traditionally, states have used "consultation exceptions" to allow physicians licensed in one state to consult occasionally with patients in another state without obtaining an additional license under specified and limited conditions. Consulting physicians are generally assumed to act under the authority of a practitioner licensed in the state of the patient, and do not have primary responsibility for the patient.

\section{Endorsement, mutual recognition, and reciprocity agreements}

Although there are differences between these three licensing models, all involve the recognition of licensure policies of one state by another state. As defined by Walker, ${ }^{26}$ endorsement agreements allow a state licensing board to issue licenses to physicians from another state if that state is determined to have equivalent licensing standards. Mutual recognition agreements enable state licensure boards to accept the licensure policies of the physician's home state. And, reciprocity agreements between states allow physicians licensed in one state to receive equal privileges in another state without having to obtain a separate license. These endorsement-type agreements are ordinarily how states grant licensure to physicians from other states. ${ }^{23}$ Several authors have made persuasive arguments for applying the above models to the practice of telemedicine. ${ }^{23,25}$

\section{Special licensure}

The special licensure approach to telemedicine requires that physicians who wish to practice telemedicine obtain an additional license exclusively for the purpose of practicing medicine across state lines. To resolve jurisdictional issues, the licensee must be subject to the regulatory authority of one state, either the state where the physician is licensed or where the patient is located. Uniform guidelines are used to evaluate physicians holding a medical li- 
cense in one state who apply for a telemedicine license.

In 1996, the Federation of State Medical Boards (FSMB) approved a Model Act that recommended adoption of state legislation to require special licensing procedures for physicians practicing medicine across state lines. Twenty states have since enacted legislation requiring special purpose licenses for telemedicine activities that cross state borders. ${ }^{28}$ The FSMB recommended that for special licenses to be effective, the licensee must be under the regulatory authority of the state in which the patient is located. The FSMB and other proponents of special licensure argue that this model preserves the current state licensure system and ensures quality monitoring and appropriate accountability over the practice of medicine. ${ }^{19}$

\section{National licensure}

Similar to a special license, national licensure for telemedicine would require a single license for the practice of telemedicine. Unless special provisions are made for state regulatory control, a national model would put the administration and licensing authority for telemedicine in the hands of the federal government. Two approaches to national licensure are possible. The first approach would entail complete federalization of licensure for telemedicine, which would not only establish federal administration of telemedicine licensing, but would also preempt all state regulatory functions in the practice of telemedicine. The second is a hybrid approach in which granting telemedicine licenses would occur at the federal level, but the states would retain authority over the practice of medicine and the ability to enforce standards of practice.

\section{CRITIQUE OF THE STATE-BASED LICENSURE SYSTEM}

The literature in support of state licensure for telemedicine consists almost entirely of broad arguments for retaining the status quo. Commentators have not critically examined the specific advantages and disadvantages of apply- ing a state licensing model in telemedicine practice. In this section, we offer a critical analysis of state-based licensure as applied to telemedicine.

\section{Advantages of state licensure}

State-based licensure possesses certain advantages. The primary advantage is the oversight function of the state, which provides monitoring of the quality of medical care provided within a state. State boards implement guidelines for obtaining medical licenses, enforce standards for the practice of medicine, sanction improper practices, and provide access to disciplinary information. ${ }^{29}$ State-based approaches to telemedicine licensure would enable the enforcement of local standards and physician oversight. They also permit statebased professional lobbies to play a larger role in the regulatory decision-making process. $^{20}$ Some proponents also argue that a state-based system encourages innovation and continuous improvement in regulation and programs as a result of testing different approaches across states. $^{29}$

Another advantage is that the state-based licensure system has become increasingly uniform since its inception in the early twentieth century. ${ }^{21}$ The current medical system operates under national standards for education, post-graduate training, and licensing examinations. Applicants for medical licensure in all states must pass a national exam, the United States Medical Licensing Exam (USMLE). However, each individual state medical board makes licensing approval decisions (which can be based on different USMLE results). ${ }^{30}$

One of the presumed advantages of a statebased system is the disciplinary ability of state medical licensing boards to enforce accountability. In reality, there is widespread criticism of the effectiveness of licensing boards to deal with substandard medical care or physician incompetence. $^{20}$ Indeed, most state licensing boards are reluctant to sanction or discipline offending physicians. Thus, arguments that state-licensure for telemedicine would maintain quality and ensure accountability may not be fully justified. 
Critique of the four state-based approaches to telemedicine licensure

The benefits of state-based licensure for medical practice, generally, are not fully applicable to telemedicine. The four state-based models described below are vulnerable to the criticism that they lack sufficient coordination and uniform standards to facilitate telemedicine practice. At minimum, the advantages do not outweigh the disadvantages.

Full Licensure: Full licensure requirements for telemedicine preserve state authority over the practice of medicine. On the surface, full licensure appears to protect both patient and physician interests, but it also poses a significant barrier to the practice of telemedicine. The process of obtaining a second license is cumbersome, and it requires additional fees. According to the American Telemedicine Association (ATA), full licensure requirements "unreasonably limit patients' rights by denying access to remote medical expertise." 31 Full licensure unduly limits patient choice and discourages physicians from engaging in interstate telemedicine, but appears currently to be the only reasonable choice for some physicians. Given the absence of clear licensure laws governing the practice of interstate telemedicine, physicians are best protected from liability if they obtain full licensure in each state in which they plan to treat or diagnose patients.

Consultation Exception: Application of the consultation exception to telemedicine would leave the current licensure system relatively unchanged. However, it would eliminate the redundancies and burdensome requirements associated with obtaining a second license. Allowing consultation exceptions for telemedicine would retain state control, but it would pose several problems. For instance, consultation exceptions routinely limit both the duration and number of patient consultations, thereby severely restricting the authority of the out-of-state physician. Also, all states mandate that all consultations be requested by a locally licensed physician. ${ }^{23}$ This would prevent a patient from seeking care directly from physicians practicing in other states.

The consultation exception for telemedicine is constrained by the conditions of the excep- tion rule which are likely to restrict patient choice. Perhaps a more significant problem is the discrepancy between states regarding what constitutes an "exception" to the state licensure laws, which creates legal uncertainty for physicians. In some states, the consultation exception is defined too narrowly for telemedicine practice. ${ }^{23}$ For example, Alabama law limits out-of-state consultations to 10 days per year. ${ }^{23}$

Endorsement, Mutual Recognition, and Reciprocity: When applied to telemedicine, endorsement, mutual recognition, and reciprocity agreements eliminate many of the inefficiencies associated with full licensure while avoiding the limitations of the consultation exception. Under these three types of agreements, physicians licensed in one state can practice telemedicine in other states without the burden of obtaining a separate license and enduring restrictions on the number of consultations or authority over patients. However, this type of licensure may exacerbate legal uncertainties and discourage physicians from practicing telemedicine across in state lines.

Not all states endorse the licenses of other states. Indeed, under current law, a physician with a license not recognized in another state could conceivably be practicing medicine without a license simply by using e-mail for consultation or to treat a patient in the distant state. ${ }^{32}$ Thus, there is a substantial burden on the telemedicine consultant to ascertain whether reciprocity agreements are recognized by the state where the patient resides. The Licensure Task Force of the Center for Telemedicine Law (CTL) described state requirements for reciprocity agreements as "time consuming, costly, and confusing." In some states, qualified physicians would be unable to practice interstate telemedicine without retaking the licensing examination or enduring other burdensome procedural requirements. ${ }^{21}$

By analogy, the state-based licensure of legal practice has long permitted attorneys licensed in one state to obtain special permission to practice in another state by petition. Usually, the out of-state attorney must be sponsored by an in-state attorney and can only practice for a specific case. As one might expect, this system actively discourages such arrangements.

Special Licensure: The special licensure ap- 
proach establishes state-defined guidelines for obtaining a telemedicine license and preserves state authority to enforce clinical standards of care and physician accountability. Proponents argue that special licensure will protect patients while minimizing costs to physicians. Special licensure may indeed ease some of the problems facing telemedicine, but it does not address the fundamental issues of divergent state standards and legal accountability that arise from any state-based licensing system.

The special licensure policies set forth in the FSMB Model Act are somewhat ambiguous and may lead to incompatible standards for practicing telemedicine. For example, the Model Act defines the practice of medicine across state lines as "any contact that results in a written or documented medical opinion and that affects the diagnosis or treatment of a patient." 22 This broad definition relies on individual state boards to apply local standards to define what constitutes the practice of medicine across state lines. The FSMB also depends on states to "define 'emergency' situations and consultations made on an 'informal or irregular basis.'"18 By relying on state-defined standards, a special licensure approach will do little to address the extant barriers to interstate telemedicine.

Summary: The advantages of a state-based system appear to be tenuous when applied to telemedicine. At a time when patients can benefit from medical expertise across state lines, the state-based licensure system acts to obviate this advantage. The prevailing incompatibility between state policies and licensure requirements presents substantial barriers to the development of interstate telemedicine.

\section{EXPLORING A NATIONAL LICENSURE SYSTEM}

\section{Need for national licensure}

American society is undergoing substantial social and economic change. Information technology has revolutionized the way we communicate, learn, conduct business, and get medical care. The policy implications of these changes are significant, requiring the need to reconsider the viability of the state-based medical licensure system.

In theory, it would not be difficult to implement national standards for the practice of telemedicine. Jost noted that "unlike professions such as law, where knowledge is state specific, training in the health care professions is science based and universal." 20 If telemedicine were to reach its full national potential, its licensure cannot be left to the states. A national approach is needed to establish and enforce uniform standards to foster the growth of a technology that has the potential to save lives and improve health care access for millions of Americans. A national licensure system will expand the market for telemedicine services, promoting both the use and development of new technologies, and simultaneously eliminate many of the legal and regulatory ambiguities that plague the present system.

\section{Objectives of national licensure}

The primary goals of national licensure for telemedicine are to allow standardized review of licensing, to maintain a central repository of information on telemedicine-related malpractice claims and verdicts, and to develop and enforce uniform standards for the practice of telemedicine.

Two possible approaches to national licensure would address these issues: (1) the complete federalization of telemedicine licensure, and (2) a joint state-federal system that would establish a set of national standards for the practice of telemedicine, but still retain state jurisdiction over professional conduct.

\section{Feasibility of a national licensure system}

The tenth amendment to the U.S. Constitution empowers each state to protect the health and safety of its citizens. Hence, states are granted the power to regulate and license healthcare providers. ${ }^{2,25,31,33}$ Although traditionally the practice of medicine has been under state jurisdiction, there is precedent for federal intervention. ${ }^{25}$ The National Practitioner Data Bank and Medicare and Medicaid reimbursement policies have already interjected a substantial federal presence into the provision of health care services. The Veteran's Admin- 
istration, Indian Health Service, Public Health Service, and the U.S. Military are other examples of health care programs that operate under federal control. And the Employee Retirement Income Security Act of 1974 (ERISA) substantially limits the ability of state legislators to regulate the managed care industry. ${ }^{34}$

Telemedicine provides a strong justification for national intervention based on the Interstate Commerce Clause of the U.S. Constitution, which restricts the ability of the states to disrupt interstate trade. ${ }^{2}$ Representative, now Senator, Wyden proposed an amendment to the Communications Act of 1995 which, based on the Commerce clause, would have prevented states from restricting interstate telemedicine consultations. This bill was ultimately withdrawn. ${ }^{35}$

National licensure is likely to receive strong opposition from medical professional lobbies, other physician organizations, and especially state licensure boards. The current state system effectively limits competition between doctors in different states, restricting patient choice. ${ }^{18}$ In most states, health professionals oversee their own licensure boards and the political power of professional organizations profoundly influences licensure policy. ${ }^{20}$ Statelevel physician groups are not likely to embrace the potential competitive impact of telemedicine. ${ }^{5}$ Telemedicine has the potential of allowing patients in either the most densely concentrated physician markets or the most isolated and rural areas to seek medical advice from health professionals across the nation. This practice is likely to threaten to the local sovereignty of many physicians.

\section{Federalization of telemedicine licensure}

Complete federalization would place the licensure process for telemedicine in the hands of the federal government. Licensing and enforcement of physician accountability for telemedicine would be administered at the federal level. If it chooses to do so, Congress could establish guidelines for obtaining a telemedicine license on the basis of national standards. An existing agency could be authorized, or a new agency created, to enforce uniform standards and maintain a central repository for disciplinary data on physicians practicing telemedicine. Under this proposal, medical malpractice cases involving telemedicine would be resolved in federal court.

A similar federalization occurred in the early 1970s following a series of pension plan collapses in the late 1960s. After determining that the state-based pension regulatory system was inadequate to protect employee pension benefits, Congress enacted the ERISA of 1974. ERISA provides a uniform system of pension requirements that are regulated by the Department of Labor.

\section{POLICY ALTERNATIVES}

\section{Proposal for a joint state-federal system}

In an era where society has consistently opposed "big government" and the preservation of states' rights is considered highly important, a proposal for national licensure is likely to be met with strong opposition. Hence, the complete federalization of telemedicine licensure is highly unlikely.

Absent some type of national licensure, however, telemedicine will not reach its full potential. For this reason, we propose a joint state-federal system in which states would retain jurisdiction over professional standards and conduct, whereas a federal agency would issue licenses only. With uniform national standards, the federal government would have authority to grant (or remove) telemedicine licensure to qualified physicians. Physicians would practice telemedicine according to uniform standards, rather than fifty sets of different state rules. However, enforcement of these standards would occur at the state level. A joint state-federal system has the potential to eliminate many of the redundant procedures that exist under a state-based approach, while preserving state control over physician accountability.

To resolve jurisdictional issues while protecting patients, state medical boards would retain the authority to sanction physicians from other states treating patients via telemedicine. As part of the licensure process, telemedicine physicians would agree to accept jurisdiction over malpractice claims in the patient's state. 
Physicians licensed to practice telemedicine would be responsible for recognizing and understanding the clinical practice guidelines and medical standards established in the distant state. Medical malpractice disputes would be resolved, as they currently are, by state courts.

Under a joint state-federal system, access to physician disciplinary information on telemedicine physicians would be maintained at the federal level. Congress may also delegate responsibility for monitoring data privacy and confidentiality to one agency. In turn, this agency would have greater authority to work with the private sector to develop security systems for interstate data transmission, and with the states to maintain state-based oversight functions. As telemedicine expands, the potential for disclosure of confidential information absent strong internal and external data security protections is all too real. Adequate confidentiality protections are, therefore, both an integral part of patient acceptability of telemedicine and a precondition for the expansion of this field.

\section{Reliance on the free market}

A dramatically different approach would be to eschew regulation altogether, and to rely on the free market to regulate telemedicine. Because medical practice has been traditionally regulated, this would be a radical departure from past practice, and one without a solid conceptual or practical justification.

A more acceptable approach might be to develop a self-regulatory mechanism for telemedicine similar to private health care accreditation. Over time, this might become an attractive corollary to a joint state-federal approach where the regulators would delegate standardsetting and accreditation functions to a private entity. For the time being, however, no such accrediting body has emerged to perform these functions. ${ }^{36}$

\section{DISCUSSION}

A discussion of national licensure has broad implications for the entire state-based medical licensing system. The purpose here, however, is not to address the separate but related issue of national licensure for medical practice. At this point, a national system for telemedicine can certainly co-exist within the larger statebased medical licensure system. Because this would only amount to a narrow exception to current licensing arrangements, joint state and federal licensing for telemedicine will not undermine the current state-based system. At least in the short term, this exception would not inhibit state licensing for any health practitioner any more than does specialty board approval.

Commerce and business transactions in the Internet Age have little consideration for geographic boundaries. New technologies effortlessly transverse state borders, posing direct challenges to state-based models of regulation. A state-based system involves substantial legal uncertainty, making it difficult to regulate individuals and corporations involved in crossstate activities. State-based oversight and monitoring of emerging interstate telecommunication technology is not only inefficient but also inappropriate.

Thus, national licensure has important policy and regulatory implications not only for telemedicine, but also for other applications of information technology typically subject to state-based control. These enterprises include distance learning and other Internet-based educational activities (medical and nonmedical), on-line banking and gambling, and on-line sales of products such as alcohol and prescription drugs. One recent study indicates that the quality of Internet medicine is uncertain, and there is potential for serious abuse. ${ }^{40}$ Indeed, on-line pharmacies have recently come under scrutiny for the unlawful sale of prescription drugs. ${ }^{37-39}$ A suit filed by the Missouri Attorney General against a Texas-based on-line pharmacy alleges that the pharmacy and its owner are violating Missouri law by providing prescription drugs without a state license. ${ }^{39}$ As with medicine, pharmacy licensure and definitions for the "practice of pharmacy" are state responsibilities. ${ }^{41}$

Continued state-based monitoring and regulation also impede the market for goods and services offered by these businesses, and can unfairly burden industries using information 
technology with legal and regulatory constraints. Numerous Internet companies have already paid consulting and legal fees to address licensure barriers and regulatory issues specific to their industry. It is clear that many crossstate enterprises have outgrown the state-based model of licensure. National licensure appears to be the key to ensuring appropriate regulation while reducing significant barriers to information-based industries.

Two other points in American history stand are analogous to this situation: the emergence of railroads in the $19^{\text {th }}$ century, and advent of mass production in the $20^{\text {th }}$ century. ${ }^{42}$ In both cases, the respective industries were transformed from basically local activities into national enterprises. In the process, both developments confronted similar regulatory challenges and drastically altered how goods and services were provided. The existing legal and regulatory structures were entirely inadequate to respond to the issues raised by the new industries. Subsequently, these structures were replaced by a mix of state and federal regulatory strategies.

\section{CONCLUSION}

At times, economic and social arrangements change so dramatically that existing regulatory mechanisms are likely to impede technological advances. The current system of medical licensure is based primarily on statutes written at the turn of the $20^{\text {th }}$ century. To respond to the changes offered by the information revolution, we need to design a new regulatory structure for the $21^{\text {st }}$ century. Licensure of telemedicine cannot remain in the hands of the states if we are to consolidate information on malpractice to protect patients, implement uniform standards, and have efficient oversight over telemedicine technology and the transfer of confidential health information. By establishing uniform standards and granting oversight authority to a central agency, a joint state-federal system can resolve issues surrounding planning and development of telemedicine systems, resulting in increased efficiency and decreased costs.

\section{ACKNOWLEDGMENTS}

We appreciate the financial support provided by the Robert Wood Johnson Foundation's Investigator Awards in Health Policy Research program. We also appreciate the helpful comments on a prior draft from Rashid L. Bashshur, Ph.D.

\section{REFERENCES}

1. Yadin D. Alternative licensure systems for telemedicine [letter to the editor]. Telemedicine I 1996;2:79-80.

2. Vyborny KM. Legal and political issues facing telemedicine. Ann Health Law 1996;5:61-119.

3. Pergament D. Internet psychotherapy: current status and future regulation. Health Matrix: I L Med Summer 1998;8:233-279.

4. Kuszler PC. Telemedicine and integrated health care delivery: compounding malpractice liability. $\underline{A m I}$ Law Med 1999;25:297-326.

5. Guttman-McCabe C. Telemedicine's imperiled future? Funding, reimbursement, licensing and privacy hurdles face a developing technology. J Contemp Health L Policy 1997;14:327-366.

6. Matak JE. Telemedicine: medical treatment via telecommunications will save lives, but can congress answer the call?: Federal preemption of state licensure requirements under congressional commerce clause authority \& spending power. Vermont L Rev 1997;22:231-255.

7. Del Junco R, Cordray J. Telemedicine prospects and perils: weighing the potentials. Fed Bull 1996;83:18-22.

8. Weissert WG, Silberman S. Health care on the superhighway: the politics of telemedicine. Telemedicine I 1996;2:1-15.

9. Western Governor's Association. Telemedicine Action Report. June 1995. Document available from: http://calvin.arentfox.com/telemed/telemed.western.html/.

10. Crowe BL. Cost-effectiveness analysis of telemedicine. L Telemed Telecare 1998;4(Suppl. 1):14-17.

11. Nitzkin JL, Zhu N, Marier RL. Reliability of telemedicine examination. Telemedicine I 1997;3:141-158.

12. Robb N. Telemedicine may help change the face of medical care in Eastern Canada. CMAI 1997;156: 1009-1011.

13. Balas EA, Jaffrey F, Kuperman GJ, Boren SA, Brown GD, Pinciroli F, Mitchell JA. Electronic communication with patients: Evaluation of distance medicine technology. L Am Med Assn 1997;278:152-159.

14. Bashshur RL. Telemedicine effects: cost, quality, and access. L Med Syst 1995;19:81-91.

15. Bashshur RL. Critical issues in telemedicine. Telemedicine J 1997;3:113-126.

16. Jones MG. Telemedicine and the national information 
infrastructure: are the realities of health care being ignored? I Am Med Inform Assoc 1997;6:399-412.

17. Sanders J, Bashshur R. Challenges to the Implementation of Telemedicine. Telemedicine Report to Congress. U.S. Department of Commerce, January 31, 1997.

18. Orbuch PM. A Western states' effort to address telemedicine policy barriers. North Dakota L Rev 1997;73:35-63.

19. Hodge JG, Gostin LO, Jacobson PD. Privacy, quality, and liability: legal issues concerning electronic health information. I Am Med Assn 1999;282:1466-1471.

20. Jost TS. Regulation of the Healthcare Professions. Chicago, IL: Health Administration Press, 1997.

21. CTL (Center for Telemedicine Law), Licensure Task Force. Telemedicine and interstate licensure: findings and recommendations of the CTL Licensure Task Force. North Dakota L Rev 1997;73:109-130.

22. FSMB (Federation of State Medical Boards). A Model Act to Regulate the Practice of Medicine Across State Lines: An Introduction and Rationale. Report of the Ad Hoc Committee on Telemedicine, April 1996. Document available from: http://www.fsmb.org/telemed.htm/.

23. Granade PF. Implementing telemedicine on a national basis-a legal analysis of the licensure issues. Fed Bull 1996:83:7-17.

24. Lipson LR, Henderson TM. State initiatives to promote telemedicine. Telemed J 1996;2:109-121.

25. Murray JA, Burger AJ. Licensure: issues and opportunities. In: The Cardiovascular Specialist and Telemedicine: Issues for Consideration. American College of Cardiology, Ad Hoc Task Force on Telemedicine, October 3, 1997. Document available from: http:// www.acc.org/healthpol/telemedicine.html/.

26. Walker JF. Telehealth a complex issue being addressed by state and federal governments. AORN I 1997;6:709-712.

27. Siwicki B. Telemedicine providers' progress impeded at the border. Health Data Management May 1999.

28. Gobis L. An overview of state laws and approaches to minimize licensure barriers. Telemedicine Today Magazine 1997;5(6).

29. Winn JR. Endorsement: state vs. national licensure. Fed Bull 1995;82:9-15.

30. "Medical Licensure in the United States," in the USMLE (United States Medical Licensing Exam) Bulletin of Information, 1996, for further information on licensing approval decisions. Document available from: http://www.usmle.org/medlic.htm/.
31. ATA (American Telemedicine Association), State Medical Licensure Committee. Draft to ATA Board of Directors. December 11, 1998. Document available from: http://www.atmeda/org/news/policy.html/.

32. Spielberg AR. Online without a net: physician-patient communication by electronic mail. Am J L Med 1999; 25:267-295.

33. Wyden R. Bring telemedicine technology to the American people. Remarks to the House of Representatives, June 30, 1995. Text available from: http://www. arentfox.com/telemed/telmed.wyden.html/ .

34. Jacobson PD, Pomfret SD. ERISA Litigation and Physician Autonomy. I Am Med Assn 2000; 283: 921926.

35. Western Governor's Association. Telemedicine Action Update. 1998. Document available from: http://www. westgov.org/wga/publicat/combar4.htm/.

36. Caruso D. Digital commerce. The New York Times November 22, 1999; $p$. C5.

37. Kalb C, Branscum D. Doctors go dot.com. Newsweek August 16, 1999;65-66.

38. Stolberg SG. From M.D. to I.P.O., Chasing virtual fortunes. The New York Times July 4, 1999; Weekend Section, p. 3.

39. BNA (Bureau of National Affairs). State AG files suit seeking to halt Internet prescription drug sales. $B N A^{\prime} s$ Health L Reporter July 15, 1999;8:1139-1140.

40. Bloom BS, Iannacone RC. Internet availability of prescription pharmaceuticals to the public. Ann Intern Med December 7, 1999;131:830-833.

41. Boatwright DE. Legal aspects of expanded prescribing authority for pharmacists. Am J Health-Syst Pharm 1998;55:585-594.

42. Jacobson PD, Pomfret SD. Establishing new legal doctrine in managed care: a model of judicial response to industrial change. U Michigan J L Reform 1999;32: 813-861.

Address reprint requests to: Peter D. Jacobson, J.D., M.P.H. University of Michigan School of Public Health 109 Observatory Ann Arbor, MI 48109-2029

E-mail: pdj@umich.edu 


\section{This article has been cited by:}

1. Linda Godleski, J. Edwin Nieves, Adam Darkins, Laurent Lehmann. 2008. VA telemental health: Suicide assessment. Behavioral Sciences \& the Law 26:3, 271-286. [CrossRef]

2. Mark A. Cwiek, Azhar Rafiq , Aamna Qamar, Charles Tobey, Ronald C. Merrell . 2007. Telemedicine Licensure in the United States: The Need for a Cooperative Regional ApproachTelemedicine Licensure in the United States: The Need for a Cooperative Regional Approach. Telemedicine and e-Health 13:2, 141-147. [Abstract] [PDF] [PDF Plus]

3. Pamela Whitten , Lorraine Buis . 2007. Private Payer Reimbursement for Telemedicine Services in The United StatesPrivate Payer Reimbursement for Telemedicine Services in The United States. Telemedicine and $e$-Health 13:1, 15-24. [Abstract] [PDF] [PDF Plus] 